\title{
El vertedero medieval de Cártama, Málaga: las cerámicas de los pozos de época emiral y califal.
}

\author{
The medieval waste dump of Cártama, Málaga: the pottery from the Emirate \\ and Caliphate pits.
}

\author{
Francisco Melero García *
}

\begin{abstract}
RESUMEN
En este trabajo se exponen los conjuntos cerámicos documentados en los pozos de época emiral y califal del vertedero medieval de Cártama, excavado entre 2005 y 2007. Los pozos aparecen sobre las ruinas tardoantiguas. En ellos se hallan conjuntos de cerámica cerrados que abarcan cronológicamente desde el siglo $\mid X$ al XV. Los conjuntos que se presentan, a diferencia de los que se datan en otros pozos a partir del siglo XIII, no son muy extensos, por lo que no aportan una tipología variada. No obstante presentan ciertas homogeneidades intrínsecas que los diferencian entre sí, y que pueden aportar interesantes datos para el estudio de la cerámica andalusí en estos períodos. También se hace hincapié en el marco geográfico donde se distribuyeron, donde no sólo hay claras diferencias con respecto a otras regiones de al-Andalus en la cerámica indígena sino, al parecer, también en la vidriada.
\end{abstract}

Palabras clave: emiral, califal, pozos vertedero, conjuntos de cerámica cerrados.

\section{INTRODUCCIÓN}

El objetivo de este trabajo es presentar los conjuntos cerámicos de los siglos IX y X documentados recientemente en la zona más antigua del casco urbano de Cártama, comparándolos, a su vez, con otros yacimientos de estratigrafías fiables de al-Andalus. Los materiales aparecen en pozos vertedero, excavados a propósito para enterrar las basuras. Es por ello, por lo que las cerámicas poseen gran interés desde el punto de vista cronológico, ya que se trata de conjuntos primarios, reunidos en un espacio

\begin{abstract}
This work sets out to study the documented groups of pottery from the Emiral and Califal epochs found in the Medieval waste dump of Cartama which was excavated between 2005 and 2007. The wells appear on the Late Ancient ruins. Therein we find distinct closed groups of pottery which, chronologically, go from the nineth to the fifteenth centuries. The groups studied, unlike those dating back to the thirteenth century in other wells, are not particularly extensive and thus do not show a varied range of characteristics. Neverthelees, they do show certain intrinsic common features that differentiate them from each other and may provide interesting data for the study of Andalusian pottery in the periods.

It's also worth pointing out their geographical distribution, where, not only are there clear differences with respect to other regions of $\mathrm{Al}$ Andalus, in terms of native pottery, but also, apparently, in glazed pottery.
\end{abstract}

Key Words: Emirate, Caliphate, dump pits, closed groups of pottery.

temporal muy acotado. Cada uno posee unas características intrínsecas marcadamente homogéneas y diferenciadoras, al mismo tiempo, con respecto a los demás, sobre todo el tipo ataifor. Esta homogeneidad se debe al carácter de conjunto primario que proporciona el hecho de que aparezcan en estratos cerrados, donde la filtración de materiales de otros períodos ha de ser mínima y, por el contrario, la presencia de la mayor parte de los tipos más representativos en cada uno de los grupos es prácticamente única, sin que aparezcan en otros estratos, ni tan siquiera como material residual.

\footnotetext{
* SÍLEX, Patrimonio Histórico-Artístico y Arqueológico S.L.L.
} 


\section{EL YACIMIENTO ARQUEOLÓGICO}

Las recientes excavaciones arqueológicas llevadas a cabo en el casco urbano de Cártama (MELERO, 2006; MELERO, 2008) proporcionan una secuencia cronoestratigráfica prácticamente ininterrumpida desde los siglos VIII - VII a. n. e. hasta el final de la ocupación islámica en el siglo $\mathrm{XV}$. Los niveles más antiguos pertenecen a un poblado de cabañas del Bronce Final sobre el que se superponen restos de un entramado urbano fechado entre los siglos $\mathrm{VI}-\mathrm{V}$ a. n. e. A éste le sucede una gran remodelación asociada a una muralla de los siglos IV - III a. n. e., que queda amortizada con rellenos de época romana republicana, sobre los que se produce una primera fase constructiva. A partir de época de Augusto se alzan grandes construcciones asociadas al foro de la ciudad romana de Cartima. Éstas, quedan amortizadas a finales del siglo II o en la I ${ }^{a}$ mitad del III. A mediados del siglo $\mathrm{VI}$ se produce otra gran edificación, que probablemente contempla en la última de sus tres fases el período visigodo. El inicio de la época medieval conlleva el abandono del solar como espacio construido, siendo sustituido por el vertedero de basuras de una población que evidentemente se encontraría en sus inmediatas proximidades.

El vertedero de Cártama consiste en la presencia de estratos con conjuntos cerrados, como ya se ha dicho, formados en cortos espacios de tiempo mediante la apertura de pozos que se van rellenando. El horizonte cultural abarca todos los siglos entre el IX y el $\mathrm{XV}$, contando en algunos casos, como veremos a continuación, con dos claros grupos diferenciados para una misma centuria, en este caso la del $\mathrm{X}$.

Con respecto a las intervenciones realizadas hasta el momento en el entorno del vertedero, son dos los solares excavados en el centro del casco urbano de Cártama (Fig. 3). Estos solares conservan de un modo desigual la estratigrafía de época medieval, debido al desarrollo urbano posterior, donde en algunos sectores se desmonta completamente al insertar los inmuebles. En esta conservación o destrucción influye el desnivel del terreno original, así como los espacios destinados a patio o corral, donde la afección constructiva ha sido menor o prácticamente nula.

La estratigrafía de época medieval, allí donde se ha conservado íntegramente, se nos presenta con una superficie sin estructuras y con abundante material revuelto, tanto antiguos escombros, principalmente formados por piedras de diverso tamaño provenientes de las estructuras tardoantiguas, como materiales muebles de diversos períodos culturales. En estos sedimentos es donde se excavan los pozos vertedero. Los de época emiral y califal, los más antiguos, se insertan directamente sobre los derrumbes tardoantiguos, mientras que los más recientes lo hacen sobre sedimentos que se van formando durante el medievo (Fig. 8).

En total se han documentado hasta el momento 16 pozos (Fig. 3) cuyos materiales permiten datarlos provisionalmente, a falta de un estudio más exhaustivo, del siguiente modo: 2 en el siglo $\mid X, 2$ en el $X, \mid$ en el $X \mid$, otro en el XII, 3 en el XIII, 6 entre finales del XIII y a lo largo del XIV y I entre la $2^{a}$ mitad del siglo XIV y a lo largo del XV. En cuanto a las dimensiones del propio pozo, se advierte un mayor tamaño a partir del siglo XII, siendo más numerosos los de época nazarí. Los materiales que aquí estudiamos pertenecen a los 4 más antiguos, constituyendo una declaración de intenciones el poder ofrecer los estudios del resto del conjunto, sin duda más variado, y que puede aportar mayores conclusiones.

\section{ESTUDIO DE MATERIALES}

\section{I) FASE EMIRAL I (UUEE 34 y 35)}

Los dos primeros pozos se corresponden con las UUEE 34 y 35. La inexistencia de las cerámicas vidriadas de la $2^{\mathrm{a}}$ mitad del siglo IX, tan abundantes en Málaga, creemos que nos sirve para marcar un momento ante quem y afianzar el grupo en la primera mitad de esta centuria.

Dentro de las marmitas encontramos dos variantes. La marmita de cuerpo estriado con 
un asa (Fig. 4. UE 35. I; UE 34. I) presenta similitud con las de Bâŷāna, que desaparecen en el cambio de la primera a la segunda fase (CASTILLO y MARTíNEZ, 1993), y que en Cártama sucede lo mismo al no volverlo a encontrar en otros contextos. En la vega de Granada (CARVAJAL, 2008) son formas parecidas las que se documentan en el Molino del Tercio, yacimiento que no pasa del siglo IX, pudiendo pertenecer a este tipo las que se encuentran el Madinat Ilbira y en el Cerro de la Mora. En la Meseta también se asemeja al tipo F.04 de la tipología de Retuerce (RETUERCE, 1998). En Córdoba son idénticas al tipo I.I.I. del arrabal de Šaqunda (CASAL et alii, 2005). El segundo tipo de marmita guarda estrecha apariencia con las conocidas "ollas valencianas" (Fig. 4. UE 34. 2) muy frecuentes al norte de Valencia (GUTIERREZ, 1996: 98, f. 31), región que en época de al-Andalus se conoció como Šara al-Andalus. El considerable asentamiento de la etnia beréber en esta zona ha llevado a algunos autores a relacionarla con estos tipos cerámicos, pero por el momento el asunto no esta claro. En el caso de Cártama se observa una clara distinción en la elaboración con respecto al resto, tratándose de un torno más tosco que los demás, pero diferente, por supuesto, de la elaboración a mano de la cazuela.

Dentro de los jarritos se documentan dos ejemplares que podrían considerarse como prototipos de otros que se van a generalizar a finales del siglo IX. El primero de ellos (Fig. 4. UE 35. 2), con trazos digitales de pintura blanca, parece una forma inicial de los jarros de cuello cilíndrico que se van a dar con diferentes variantes a lo largo de todo el medievo adalusí. En Málaga (ACIÉN et alii, 2003), los encontramos a finales del siglo IX ya desarrollados, tanto vidriados como sin vidriar. En Marroquíes Bajos (PÉREZ et alii, 2003: 404, f. 10) se dan formas algo más evolucionadas que la nuestra para la $2^{\text {a }}$ mitad del siglo IX. En contextos de los siglos IX-X encontramos piezas parecidas con pintura en blanco, aunque con boca trilobulada, en Almuñecar (GÓMEZ, 1998: 417-42I). Un segundo jarrito (Fig. 4. UE 34.4) es más pequeño y está elaborado de un modo más tosco. Podría consistir en otro prototipo de los jarritos vidriados pequeños que se van a dar en Marmuyas (NAVARRO, 1991: 54, f. 6) O Cercadilla (FUERTES, 2002: 57, f. 102), ya en el siglo X.

El tipo de cazuela ( Fig. 4. UE 35.4), a mano, también definida como panera (CARVAJAL, 2008: 227), con posible asa horizontal, podría considerarse como de tradición indígena. Su pared recta y gruesa puede compararse con un ejemplar de Bezmiliana (ACIÉN, 1986: 256, f. 3), y también con otro del Tolmo de Minateda (GUTIÉRREZ et alii, 2003: 154, f. 22, I) para el siglo IX. Este tipo no se documenta en la Meseta. Parece que la continuidad de esta forma a finales de esta centuria va perdiendo la rectitud, siendo las paredes más curvas, como nos demuestran las tipologías de Baŷyāna (CASTILLO y MARTíNEZ, 1993: 83) O C/ Especerías en Málaga (ĩ̃NIGUEZ y MAYORGA, 1993: 134), mientras que en el siglo $X$ las paredes acaban siendo más delgadas y decididamente curvas como vemos en Marmuyas (NAVARRO, 1991: 56).

El anafre o reposadero (Fig. 4. UE 35. 5) consiste en una forma que no aparece en las tipologías emirales consultadas, siendo característico de momentos más avanzados, pudiendo responder a un anafre por la mueca interna que presenta, pero dado lo poco que se posee de la pieza también a un reposadero cuyo paralelo lo encontramos en Madinat al-Zahrā' (VALLEJO y ESCUDERO, 1998: 166, f. 34).

Un conjunto de aspecto diferete es el de los cuencos con pitorro y los de perfil en " $\mathrm{S}$ ", ambos en pasta clara. El primero (Fig. 4. UE 35. 6) consiste en una pieza de tradición hispanorromana característica del ámbito regional del sureste que nos ocupa, pudiendo pertenecer a los estratos anteriores bizantino-visigodos en los que se introduce el pozo. Emparentado con la forma T26.I de Gutiérrez (GUTIERREZ, 1996: 1 19, f. 45), donde nos dice que los ejemplares de la Cora de Tudmir son muy escasos, otorgándole una cronología entre el siglo VI y el VIII. Tipos parecidos los encontramos en Valencia, tanto en l'Almoina como en la Cárcel de San Vicente, en contextos de finales del siglo $\mathrm{VI}$ y a lo largo de todo el VII (PASCUAL et alii, 2003: I05, f. 30). Esta forma perdura con posterioridad a lo largo de todo el medievo, por lo que requiere de un estudio más concreto. Con respecto a 
los cuencos de perfil en "S" (Fig. 4. UE 34. 5, 6) se trata de una pieza no lo suficientemente documentada dentro de las tipologías de la antigüedad tardía e inicios de la época medieval. Sus pastas son claras y a torno, siendo los cuencos carenados de época visigoda con los que guarda cierta afinidad, característicos del interior peninsular '. Algunos ejemplares de Montefrío (MOTOS, 1993: 21 I, f. I) son prácticamente idénticos, así como otros de la Vega de Granada (CARVAJAL, 2008: 228), mientras que en Baŷỹāna (CASTILLO y MARTíNEZ, 1993: 83), las clasificadas como cazuelas, de pastas rojizas, guardan también cierta similitud.

\section{2) FASE EMIRAL II (UE 33)}

La fase emiral más tardía viene definida, como la califal, por los ataifores, que nos muestran las principales diferencias. Otros tipos hunden sus raíces en la etnia indígena, como la cazuela a mano/torneta vidriada por el interior o las marmitas de borde entrante.

Dentro de los ataifores, documentamos un grupo en el que se observa que ya no existen los primeros conjuntos con vidriados oscuros carentes de rebordes y repies, formas adscritas al primer período que en este marco regional podría definirse como una fase emiral temprana para estos tipos, en contraposición con un segundo período que podríamos considerar como una fase emiral más avanzada, donde estos vidriados van a generalizarse en melados menos oscuros. En cuanto a la decoración se producen elementos principales como los que se dibujan en la cara interna del fondo del ataifor junto a otros secundarios que se trazan bajo el borde. En la forma, encontramos la presencia de rebordes y repies anulares. En cuanto a estos últimos elementos, se ha venido asociando su aparición a datas de finales del siglo $\times \circ$ inicios del Xl; sin embargo, algunas publicaciones de Almería o Málaga parecen contradecir este planteamiento, línea que se opta en este estudio, pensando que la inexistencia del verde y manganeso es un factor más fuerte a la hora de ubicar este conjunto como previo al período califal ${ }^{2}$. Para todo ello, se expone una propuesta de evolución, en base a los hallazgos con que contamos, que pretende servir de marco para situar los ejemplares de Cártama.

Posiblemente, el estrato más antiguo donde aparece el ataifor vidriado es el Nivel I de Bâेȳāna (CASTILLO y MARTíNEZ, 1993:Im. IV), asociado a una cronología anterior a la expansión urbana que se va ha producir desde inicios del siglo $X$ en este lugar, y por tanto a la que se le podría dar un margen aproximado del último 1/4 del siglo IX $X^{3}$. Estos ataifores, que no tienen reborde ni pie anular, son las formas más sencillas: bajos, con fondos planos o convexos y a veces con carenas tanto internas como externas no muy destacadas. La decoración pictórica es inexistente y los vidriados, que no cubren la pieza entera (donde podríamos ver un signo de su aplicación inicial) suelen ser en verde por el interior y melados al exterior.

Un paso inmediatamente posterior podría ser el testar malagueño de C/ Especerías (IINIIGUEZ y MAYORGA, 1993) donde el tipo II se encuentra muy próximo a los almerienses, pero donde los tipos III y IV, con paredes más altas, constituirían un avance. La decoración de estos tres se generaliza a base de líneas onduladas bajo el borde y motivos centrales vegetales muy definidos, salvo el del tipo III, con una línea excisa interior que recuerda a los círculos incisos, interiores también, de Baŷyāna. El contraste que apunta hacia una evolución decisiva lo constituiría el tipo I, donde aparecen dos elementos que van a caracterizar cuadros

\footnotetext{
I Incluimos referencias aparecidas en Anejos de AespA XXVIII (2003) (LARRÉN, H. et alii: 273-306) para la cuenca del Duero; (VIGILESCALERA, A.: 37I-387) para la comunidad del Madrid; (FUERTES, Ma. C. e HIDALGO, R.: 505-540) para Córdoba.

2 Por otro lado puede que la diferencias principales entre los grupos precalifales y postcalifales acaben cristalizando en un perfil más hemiesférico de los más recientes y produciéndose los más antiguos sólo en los alfares más meridionales de la península. Así, por ejemplo, en los repertorios de los siglos XI y XII documentados en la Casa de los Tiros, Granada (RODRÍGUEZ, I999) los perfiles son más hemiesféricos que los aquí presentados.

3 Fuera de contextos meridionales de Pechina y Málaga, sólo en Jaén (PÉREZ, 2003: 76-77) aparecen estos ataifores vidriados para la $2^{\text {a }}$ mitad del siglo IX, pudiéndose tratar perfectamente de importaciones.
} 
tipológicos más evolucionados como son los trazos difuminados y los rebordes. El vidriado de este tipo I es monocromo en verde y achocolotado, o bicromo con chocolate al interior y melado verdoso o verde al exterior.

Un reciente estudio sobre diferentes niveles emirales de Málaga (ACIÉN et alii, 2003) nos ofrece un nuevo conjunto donde se advierten diferencias palpables con respecto a Especerías. Éstas vienen marcadas por una mayor presencia del melado frente al chocolate y verde, pero sobre todo por la aparición de dos motivos decorativos secundarios muy característicos como son las palmerolas y los círculos concéntricos u óvalos. Por otro lado la línea ondulada que aparece bajo el borde de uno de los tipos se diferencia de las de Especerías por acabar en arista en la parte superior, lo que nos recuerda en cierto modo a los ejemplares califales que se nos presentarán con medios círculos bajo el borde. Los trazos son siempre en esta tipología sinuosos o con chorreones.

Estos tres conjuntos podrían definirse como tipos tempranos, encuadrados posiblemente con una cronología de la $2^{\mathrm{a}}$ mitad del IX que se adentraría en el X. A este período le sucedería otro que podríamos definir como tipos más avanzados, a los que pertenecería el pozo UE 33 de Cártama ${ }^{4}$. Aquí, los tonos de vidriado oscuro en verde y chocolate han desaparecido casi por completo asistiendo al predominio del melado. En cuanto a las formas, los rebordes y pies anulares se imponen, no presentando nuestro pozo forma ajena a estos tipos. En la decoración, asistimos a dos modelos, los figurados (Fig. 5. I) con trazos pespunteados, con las palmerolas y óvalos bajo el borde, y el motivo central, en este caso, posiblemente zoomorfo. Forma y motivos decorativos, que no tienen por qué ir juntos, tienen sus paralelos en conjuntos a caballo entre la época emiral y califal. Así, sin rebordes y presumiblemente sin pies anulares encontramos los motivos secundarios sobre melado en Málaga para el último cuarto del siglo IX. Lo mismo, con motivo central diferente, se encuentra en Cercadilla (FUERTES, 2002: 69, f. 44), en contexto califal de la $2^{a}$ mitad del siglo $X$. Con reborde y pie anular lo encontramos en Marmuyas (NAVARRO, 1991: 50, f. 2), idéntico salvo por el motivo central, encuadrándose en un siglo X; y en Baŷỹāna para la segunda fase, $I^{a}$ mitad del siglo $X$, con forma similar pero con decoración variable ya que si bien tenemos las palmerolas, los motivos centrales son diferentes, así como el vidriado sólo melado al exterior y con un interior ya en verde y manganeso sobre blanco. El otro modelo decorativo es el de trazos con chorreones, en este caso radiales (Fig. 5. 2, 3). Los tipos decorativos de Cártama se completan con otro fondo con pie anular melado al exterior y achocolatado al interior (Fig. 5. 4), donde se disponen partículas en manganeso.

Fuera de los ataifores, sólo existe vidriado un cuello de redoma (Fig. 5. I5), pieza frecuente en estos períodos.

Se documentan dos ejemplares de jarro de cuello cilíndrico. El primero (Fig. 5. 5) tiene paralelos en Cartagena (MURCIA y GUILLERMO, 2003: 207, f. 19), donde en momentos de abandono de época emiral se documenta una pieza de forma, pasta y pintura similares, si bien, ésta última consiste en tres trazos en rojo pintados en horizontal bajo el borde en vez de la trama de red de Cártama. En Montefrío (MOTOS, 1993: 222, f. 8) para momentos entre el siglo IX y $X$ se localiza un conjunto muy parecido con decoraciones variadas de tipos y colores. El segundo jarro (Fig. 5.6) es más característico por lo marcado del torno en su cara interna y el uso de pintura negra sobre la que se plasman trazos digitados de pintura blanca. El paralelo prácticamente exacto se documenta en el mismo conjunto, referido para la pieza anterior, de Montefrío. También es similar una pieza de Cercadilla dentro del grupo de Jarros/ Jarras (FUERTES, 2002: 38, f. 7). Con respecto a la pared con arranque de asa y el fondo ligeramente convexo (Fig. 5. 7, 8), son dos formas que asociamos a este tipo. 4 Similares a este grupo son los documentados anteriormente en la Villa romana de Manguarra, también en el término municipal de
Cártama (ALIJO, 1979: 217-222), que el profesor Acién señala dentro de las primeras cerámicas vidriadas (ACIÉN, 2007: 39). 
Otro grupo con bastantes variantes es el de las marmitas u orzas, presentando cuatro tipos. Los dos primeros (Fig. 5. 9, I0) apenas cuentan con el borde, por lo que poco se puede decir de ellos, si bien el segundo, con borde de sección triangular, se asemeja en cierto modo a las de paredes estriadas del período anterior, pero el desarrollo del cuello se va estrechando mucho más. En cuanto al tercer tipo (Fig. 5. I I), quizás más bien una orza, de cuello vertical estrangulado y borde exvasado y biselado, es un tipo poco frecuente cuyo único paralelo, y siempre aproximado, lo encontramos en el Castillejo de Olías (GÓMEZ, 1998: 299). Presenta trazos digitados con pintura blanca, que es algo muy común en los conjuntos califales. Finalmente, la marmita de borde entrante (Fig. 5. $12,13)$ es un tipo de los más frecuentes en la región del sur de Levante y Andalucía Oriental que nos ocupa, y que se vinculan claramente a tradición indígena. El paralelo más antiguo lo encontramos en el Tolmo de Minateda (GUTIERREZ et alii, 2003), entre la $2^{a}$ mitad del siglo VII e inicios del VIII. La perduración de su forma está presente en contextos de finales del siglo XII $\circ I^{a}$ mitad del XIII en Murcia (BELLón y MARTÍNEZ, 2007).

En cuanto a las cazuelas, encontramos dos tipos, uno carenado (Fig. 6. 16), a torno, cuyos paralelos están presentes en la provincia, como los documentados en Ronda (ACIÉN et alii, 2003: 438), si bien no se ajustan con exactitud. El segundo tipo (Fig. 6. 17) es mucho más interesante por constituir una adaptación a esta forma de las marmitas de borde entrante. Efectivamente, guarda afinidad con aquel tipo respecto de la forma de su solero plano y su borde recto y entrante. En cuanto a su elaboración está realizado a mano/torneta. Pero la excepcionalidad mayor es la novedad de incluir el vidriado interior en su acabado. No existen paralelos publicados de este tipo exacto. En C/ Santa María, n 19 de Málaga (MELERO, 2003) apareció otro similar en los mismos contextos, si bien con una cronología menos precisa. La forma, como se indica, pensamos que es una adaptación de la marmita, lo que unido a su elaboración a mano/torneta, señala que es un tipo que se puede incluir en la tradición indígena, donde se ha adoptado la técnica del vidriado.
Sobre los alcadafes (Fig. 6.21) y los anafres o reposaderos (Fig. 6. 20), su presencia y forma es algo muy común ya en estos niveles, al igual que las tinajas (Fig. 6. 22, 23). En cuanto a las cerámicas elaboradas a mano (Fig. 6. 18, 19) aparecen dos fragmentos donde el borde puede pertenecer a una cazuela de perfil esférico con borde recto y biselado, mientras que sobre el fondo plano sólo se puede decir que pertenece a un gran recipiente, quizás una tinaja. El resto del conjunto consiste en materiales residuales que abarcan un arco entre época ibérica y la tardoantigüedad, con una sigillata africana tipo Hayes 87 B fechada a principios del siglo VI, o una T.S.H.T. de cronología similar.

\section{3) FASE CALIFAL (UE I8)}

Los ataifores de este pozo pueden dividirse en tres tipos, donde todas las decoraciones presentan ya, en diversos modos, el verde y manganeso. Un primer grupo sería el de los ataifores melados de paredes altas (Fig. 7. I, 2); un segundo estaría formado por los ataifores melados de paredes bajas (Fig. 7. 3, 4); mientras que el tercero lo constituiría el ejemplar vidriado en blanco (Fig. 7. 8). Una diferencia con respecto al período anterior que abarca la totalidad del conjunto es la ausencia tanto de reborde como de pie anular. Los bordes son siempre indiferenciados, como una terminación redondeada de la pared. Los fondos son planos o ligeramente convexos.

En cuanto al resto de la cerámica vidriada, aparece un fondo y cuerpo de redoma (Fig. 7. 18) melada junto a un jarrito decorado en verde $y$ manganeso (Fig. 7. I7) que constituye una pieza singular. El tipo, tanto por su forma como por el modelo decorativo, cuenta con otros parecidos repartidos por la geografía del sureste peninsular que nos permite apreciar la variedad que sobre un mismo tipo pudieron elaborar diferentes talleres a lo largo del período emiral, así como su posterior y completa adaptación a los modelos decorativos de época califal.

En el grupo de jarros/jarritos encontramos el de cuello cilíndrico (Fig. 7.9) ya plenamente evolucionado, con trazos digitados de pintura blanca. A esta forma podría pertenecer un 
fondo plano con arranque de cuerpo globular (Fig. 7. 10) y una pared con hombro marcado cuya superficie exterior se encuentra espatulada (Fig. 7. 16). Junto a este tipo, encontramos otro de menor tamaño con cuerpo globular y boca trilobulada (Fig. 7. II) con los trazos digitados en pintura blanca, cuyo paralelo lo podemos encontrar en el número 2 de la UE 35, pero algo más pequeño. Piezas parecidas son muy frecuentes en estos contextos. Así por ejemplo las encontramos en Málaga (ACIÉN et alii, 2003: 428, f. 12) para época emiral, en Cercadilla (FUERTES, 2002: 132, f. 100) dentro del grupo de "Piezas de pequeño tamaño", y en Almuñecar (GÓMEZ, 1998: 420, f. 46). Parece una forma más propia de la Andalucía Oriental que de la zona levantina.

Quizás importados, pues su acabado a torno es de mejor calidad, contrastando con el resto, son tres bordes con paredes exvasadas y labios vueltos hacia dentro. Dos de ellos (Fig. 7. 13, 14), con pintura roja al exterior, son diferentes al tercero (Fig. 7. 15), con borde diferenciado, engrosado, más vertical y sin pintura. La forma de los dos primeros se asemeja a las identificadas como tambores, que cuenta con una amplia dispersión encontrándose en Cercadilla (FUERTES, 2002: 142, f. I07) o en zonas más alejadas como la Meseta (RETUERCE, 1998: 331).

En cuanto al tipo candil (Fig. 7. 19) se documenta una pieza propia de este período, con piquera desarrollada y asa que se introduce dentro de la boca. Por último, en el alcadafe (Fig. 7. 20) destaca la presencia de visera al exterior, quizás de tradición tardoantigua .

\section{CONCLUSIONES}

Los materiales de los pozos vertedero son los primeros que se documentan durante los siglos IX y X en la propia localidad de Cártama, si bien se suman a los documentados anteriormente en la villa romana de Manguarra (ALIJO, 1979). Los conjuntos no son muy extensos, echándose en falta la presencia de determinados tipos no presentes pero que debieron circular junto a éstos. Al mismo tiempo, la ausencia de los ataifores de vidriados oscuros, bien documentados en la cercana Málaga, pensamos que se debe a la falta de un subperíodo emiral centrado en la $2^{a}$ mitad del siglo IX. Por todo ello concluimos que los conjuntos presentados no nos permiten realizar por el momento unos cuadros cronotipológicos aceptables para la cerámica de Cártama en estos períodos.

Sin embargo, en este marco local se comienza a arrogar luz desde la arqueología sobre lo que se desprendía de los textos de autores árabes coetáneos o de poco tiempo después, que habían definido el lugar como un núcleo urbano anterior, donde se van a asentar árabes yemeníes que van a crear el iqlim o distrito de Cártama, entendido como una comarca natural, en llano, con buenas tierras de regadío y con una población dispersa en alquerías o aldeas.

Con respecto al inicio de la fase islámica, sabemos pues que se produce una continuidad del enclave como lugar habitado, aunque con éste se abandonan los edificios construidos en época bizantina y probablemente reaprovechados en la visigoda, convirtiéndose el solar excavado en una zona de vertedero donde se abren a lo largo de todo el medievo pozos para ocultar las basuras. Este hecho, que se produce en otros lugares de al-Andalus, responde a unas pautas concretas en la reocupación de antiguos núcleos urbanos binzantino-visigodos como lo fueron Antequera (NAVARRO et alii, 200I) o Ceuta (FERNÁNDEZ, 200I) en los que se produce la misma ubicación de vertederos en zonas anteriormente edificadas. Pautas que implican una población en zonas inmediatas al basurero, que en lo que se refiere a Cártama están por descubrir en lo que sería el asentamiento bajo, en contraposición al alto que debería situarse en el interior del castillo, hoy en día todavía desconocido desde el dato arqueológico. Lo que sí se deduce del registro arqueológico, es la progresiva consolidación del núcleo poblacional de Cártama, como puede verse en el mayor número de cerámicas que se vierten en cada pozo conforme avanza la época. Así, el vertido del siglo IX es notablemente menor al que se produce en cada uno de los pozos del siglo $X$, lo que va a ir en aumento en la época de taifas y sobre todo entre los siglos XIII y XV, donde la Cártama nazarí debió alcanzar su cenit poblacional. 
El repertorio formal y la comparación de los tipos con otros conjuntos peninsulares nos permite ubicarlo dentro de las producciones que se van a dar a lo largo del alto medievo andalusí en el sureste, situándonos desde el primer conjunto en un momento avanzado que presenta gran diversidad de formas, e incluso de tipos. En este sentido, si comparamos los tres conjuntos, podemos observar una mayor estandarización a nivel peninsular del grupo califal, donde la mayoría de los tipos están ya presentes en otras zonas regionales.

En el primer conjunto, es de destacar la variedad relacionada con el tipo marmita, documentando dos, al que hay que sumar un tercero, el de base plana y borde entrante, muy común a esta región y cuya ausencia no se debe a la falta de producción en estos momentos. El tipo de marmita de cuerpo estriado es un producto bien definido en yacimientos no sólo de este marco regional, sino fuera de él, encontrándolo presente en el Guadalquivir (CASAL et alii, 2005) y en zonas limítrofes como la Vega de Granada (CARVAJAL, 2008). Su cuerpo estriado está muy vinculado a la tradición hispanorromana, desapareciendo de modo generalizado en todos los yacimientos en el transcurso del siglo IX al X. Por el contrario, el tipo "olla valenciana", de cuello más pronunciado, es una forma más extraña en este marco regional, debiendo esperar a su constatación en otros registros arqueológicos para poder extraer conclusiones. Con respecto a la cazuela a mano, es un ejemplo de forma regional, que se puede vincular a producciones indígenas, desapareciendo a medida que van evolucionando las producciones emirales, no siendo ya frecuente en el siglo IX.

Con respecto al conjunto emiral avanzado, la ausencia del verde y manganeso en los vidriados, esencialmente en el tipo ataifor, nos parece un argumento fundamental para situarlo en este momento. El contraste, además, en estos tipos con respecto a los del conjunto califal por la presencia de rebordes y pies anulares nos parece significativo y determinante para abordar diferencias no sólo a nivel local, sino sobre la extensión de esta forma en otras regiones de al-Andalus. En este sentido, creemos que la evolución y dispersión de estos tipos, tal y como se manifiesta en otros yacimientos peninsulares, es muy desigual. Así, los documentados en nuestro conjunto pueden ser testimonio de un proceso regional de evolución hacia nuevas formas, que se van a ver condicionadas, en cierto modo, cuando se impongan los tipos en verde y manganeso, y de los que nuestro estrato califal es un buen ejemplo. En cuanto a los jarritos/as pintados, responden a variantes del principal tipo de jarro andalusí, el de cuello cilíndrico, que se va a extender y perdurar de tal modo que constituye uno de los tipos más representativos a lo largo de todo el medievo andalusí. Si durante el período nazarí va a derivar en las jarritas pajizas pintadas o esgrafiadas, creemos que los tipos documentados en la UE 33 pueden partir de prototipos o derivaciones tempranas. También apreciamos producciones propias de nuestro ámbito. Es el caso de la orza pintada con trazos digitales, cuya forma es irreconocible en otros yacimientos, o la cazuela producida a mano/torneta con vidriado interior, que es un producto nuevo derivado de los tipos de solero plano y borde entrante que sólo se van a producir en el sureste.

La mayor parte de las formas del conjunto califal presentan ya una gran homogeneidad con respecto a los conjuntos andalusíes de la península. Las diferentes variantes de ataifores en verde y manganeso con solero plano - ligeramente convexo, los jarros de cuello cilíndrico, la formas asociadas a tambores, las encontramos extendidas por toda la geografía andalusí. Los ataifores, si bien tanto los melados como el blanco presentan verde y manganeso, no cuentan ni con rebordes ni con pies anulares, constituyendo acabados y formas una contradicción con respecto al conjunto emiral avanzado. ¿Es azar o ambos pozos quieren significar algo? Creemos que el hecho de proceder de conjuntos cerrados proporciona una información que no apreciamos cuando documentamos sedimentos corrientes cuya formación ha estado expuesta a intrusiones o a formaciones más longevas. Una información que puede estar vinculada a dos momentos distintos en la distribución de este producto. Uno en época emiral, cuando las producciones locales cuentan con mayor autonomía, y por 
ello poseen características que son fruto de una evolución que no se ha dado en otras regiones de al-Andalus. El otro en época califal, tras el desarrollo del verde y manganeso, cuando el ataifor vidriado se produce a gran escala en talleres del interior, sobre todo cordobeses desde donde se irradia por todo al-Andalus, condicionando las producciones locales de otras regiones como sería el caso de Málaga y sus alrededores (Cártama).

\section{BIBLIOGRAFÍA}

ACIÉN ALMANSA, M. (1986): "Cerámica a torno lento en Bezmiliana. Cronología, tipos y difusión", I CAME (Huesca, 1985), vol. IV. Zaragoza, 243-267.

ACIÉN ALMANSA, M. (1989): "Poblamiento y fortificación en el sur de al-Andalus. La formación de un país de husun", III CAME (Oviedo, 1989). vol. I: Ponencias. I35- I 50.

ACIÉN ALMANSA, M. (2007): La Málaga Musulmana (VIII-XIII), Historia de Málaga. Málaga.

ACIÉN ALMANSA, M; CASTILLO GALDEANO, F;; FERNÁNDEZ GUIRADO, M․ l.; MARTÍNEZ MADRID, R.; PERAL BEJARANO, C. y VALLEJO TRIANO, A. (1995): "Evolución de los tipos cerámicos en el S. E. de al-Andalus", Vème Colloque International sur la céramique médiévale en Méditerranée Occidentale (Rabat, 1991). 125-149.

ACIÉN ALMANSA, M.; CASTAÑO AGUILAR, J. M.; NAVARRO LUENGO, I.; SALADO ESCAÑO, J. B. y VERA REINA, M. (2003): "Cerámicas tardorromanas y altomedievales en Málaga, Ronda y Morón" en L. Caballero, P. Mateos y M. Retuerce (eds.), Cerámicas tardorromanas y altomedievales en la Península Ibérica, Anejos de AespA. XXVIII. Madrid, 4 I I-454.

ALIJO HIDALGO, F. (1979): "Cerámica musulmana en una villa romana del Bajo Imperio en Cártama (Málaga), Mainake, I. Málaga, 217-222.

BELLÓN AGUILERA, J. y MARTíNEZ SALVADOR, C. (2007): "Las cerámicas medievales tardías de Murcia. Una nueva propuesta de adscripción cronológica para los materiales del siglo XIII", Arqueología y territorio medieval. 14. Jaén, 139-162.

CARVAJAL LÓPEZ, J. C. (2008): La cerámica del Madinat Ilbira (Atarfe) y el poblamiento altomedieval de la Vega de Granada. Granada.

CASAL, Ma. T.; CASTRO, E.; LÓPEZ, R. y SALINAS, E. (2005): "Aproximación al estudio de la cerámica emiral del arrabal de Šaqunda (Qurtuba, Córdoba)", Arqueología y territorio medieval. 12.2. Jaén, I89-235.

CASTILLO GALDEANO, F. y MARTíNEZ MADRID, R. (1993): "Producciones cerámicas en Baŷyāna", en A. Malpica (ed.), La cerámica altomedieval en el sur de al-Andalus, Monografía Arte y Arqueológia Universidad de Granada. Granada, 67-II6.
FERNÁNDEZ SOTELO, E.A. (200 I): Los silos en la arqueología ceutí (I), Transfetana. Monografías. $n^{\circ}$ 7. Ceuta.

FLORES ESCOBOSA, I. y MUÑOZ MARTÍN, Mª. M. (1993): "Vivir en al-Andalus", Exposición de cerámica. S. IX-XV. Almería.

FLORES ESCOBOSA, I.; MUÑOZ MARTÍN, Ma. M. y LIROLA DELGADO, J. (1998): "Las producciones de un alfar islámico en Almería" La cerámica andalusí. 20 años de investigación. Arqueología y territorio medieval. 6. Granada, 207-239.

FUERTES SANTOS, Mª C. (2002): La cerámica califal del yacimiento de Cercadilla, Córdoba. Arqueología monografías. Cercadilla. Sevilla.

FUERTES SANTOS, Ma. C. e HIDALGO PRIETO, R. (2003): "Cerámicas tardorromanas y altomedievales de Córdoba" en L. Caballero, P. Mateos y M. Retuerce (eds.), Cerámicas tardorromanas y altomedievales en la Península Ibérica, Anejos de AespA XXVIII. Madrid, 505-540.

GÓMEZ BECERRA,A. (1998): El poblamiento altomedieval en la costa de Granada, Nakla Colección de Arqueología y Patrimonio. 3. Motril.

GUTIERREZ LLORET, S. (1996): La cora de Tudmìr de la antigüedad tardía al mundo islámico. Poblamiento y cultura material. Colletion de la casa de Velásquez. 57. MadridAlicante.

GUTIÉRREZ LLORET, S.; GAMO PARRAS, B. y AMORÓS RUIZ,V. (2003): "Los contextos cerámicos altomedievales del Tolmo de Minateda y la cerámica altomedieval en el sudeste de la Península Ibérica" en L. Caballero, P. Mateos y M. Retuerce (eds.), Cerámicas tardorromanas y altomedievales en la Península Ibérica, Anejos de AespA. XXVIII. Madrid, 119-168.

IÑIGUEZ SÁNCHEZ, Ma. C. y MAYORGA MAYORGA, J. F. (1993): "Un alfar emiral en Málaga", en A. Malpica (ed.), La cerámica altomedieval en el sur de al-Andalus, Monografía Arte y Arqueología Universidad de Granada. Granada, | 17-138.

LARRÉN, H.; BLANCO, J. F.; VILLANUEVA, O.; CABALLERO, J.; DOMÍNGUEZ, A.; NUÑO, J.; SANZ, F. J.; MARCOS, G. .:; MARTÍN, M. A. y MISIEGO, J. (2003):" "Ensayo de sistematización de la cerámica tardoantigüa en la Cuenca del Duero" en L. Caballero, P. Mateos y M. Retuerce (eds.), Cerámicas tardorromanas y altomedievales en la Península Ibérica, Anejos de AespA. XXVIII. Madrid, 273-306.

MANZANO MORENO, E. (2003): "Conclusiones. La cerámica de los siglos oscuros" en L. Caballero, P. Mateos y M. Retuerce (eds.), Cerámicas tardorromanas y altomedievales en la Península Ibérica, Anejos de AespA. XXVIII. Madrid, 54I-557.

MARTíNEZ RODRÍGUEZ, A. (1993): "El horno califal de la calle Rojo, Lorca", Verdolay. Revista del Museo de Murcia. 5. Murcia, I43- I55.

MELERO GARCÍA, F. (2003):Memoria Final de E. A. U. en la Calle Santa María, n 19 (Málaga, Casco Histórico). Informe inédito de la Delegación Provincial de Cultura de Málaga. Junta de Andalucía. 
MELERO GARCÍA, F. (2006): Memoria Final de E. A. P. en la Futura Casa de la Cultura. Cártama, Málaga. Informe inédito de la Delegación Provincial de Cultura de Málaga. Junta de Andalucía.

MELERO GARCÍA, F. (2008): Memoria Final de I. A. P. en Plaza del Pilar Alto, esquina Plaza de la Constitución, Cártama (Málaga). Informe inédito de la Delegación Provincial de Cultura de Málaga. Junta de Andalucía.

MOTOS GUIRAO, E. (1993): "La cerámica altomedieval de "El Castillón" (Montefrío, Granada)" en A. Malpica (ed.), La cerámica altomedieval en el sur de al-Andalus, Monografía Arte y Arqueología Universidad de Granada. Granada, 207-237.

MURCIA MUÑOZ, A. J. y GUILLERMO MARTÍNEZ, M. (2003): "Cerámicas tardorromanas y altomedievales procedentes del teatro romano de Cartagena" en L. Caballero, P. Mateos y M. Retuerce (eds.), Cerámicas tardorromanas y altomedievales en la Península Ibérica, Anejos de AespA. XXVIII. Madrid, I69-223.

NAVARRO LARA, M. R. (|99|): "La cerámica de Marmuyas" Cuadernos de la Alhambra. vol. 27. Granada, 27-64.

NAVARRO LUENGO, I.; FERNÁNDEZ RODRÍGUEZ, L.-E.; SUÁREZ PADILLA, l.; SOTO IBORRA, A.; SANTAMARÍA GARCÍA, J.A. y SÁNCHEZ HERRERA, J. M. (200I): "Estudio de los materiales cerámicos de época medieval de la excavación arqueológica de las termas romanas de Santa María (Antequera, Málaga)" Revista de Estudios Antequeranos. vol. I 2. Antequera, 305-327.

NAVARRO PALAZÓN, J. (1986): La cerámica islámica de Murcia. vol I. Catálogo. Murcia.

NAVARRO PALAZÓN, J. (1990): "Los materiales islámicos del Alfar Antiguo de San Nicolás de Murcia", Fours de Poitiers et "Testares" Medievaux en Méditerranée Occidentale. Méthodes et resultats. Madrid, 29-43.
PACHECO PASCUAL, J.; RIBERA I LACOMBA, A. V. y ROSELLÓ MESQUIDA, M. (2003): "Cerámicas de la ciudad de Valencia entre la época visigoda y omeya (siglos VI-X)" en L. Caballero, P. Mateos y M. Retuerce (eds.), Cerámicas tardorromanas y altomedievales en la Península Ibérica, Anejos de AespA. XXVIII. Madrid, 67-I 17.

PÉREZ ALVARADO, S. (2003): Un indicador arqueológico del proceso de islamización. Las cerámicas omeyas de Marroquíes Bajos. Jaén.

PÉREZ ALVARADO, S.; MONTILLA TORRES, I.; SALVATIERRA CUENCA, V. y CASTILLO ARMENTEROS, J. C. (2003). "Las primeras cerámicas de Marroquíes Bajos (Jaén) entre la tardoantigüedad y el Islam" en L. Caballero, P. Mateos y M. Retuerce (eds.), Cerámicas tardorromanas y altomedievales en la Península Ibérica, Anejos de AespA. XXVIII. Madrid, 389-4I0.

RETUERCE VELASCO, M. (1998): La cerámica andalusí de la Meseta. Madrid.

RODRÍGUEZ AGUILERA, Á. (1999): "Estudio de la producciones postcalifales del alfar de la Casa de los Tiros (Granada). Siglos XI-XII. Arqueología Medieval. 6. $10|-| 2 \mid$.

VALLEJO A. y ESCUDERO J. (1998):"Aportaciones para una tipología de la cerámica común califal de Madinat al-Zahra" La cerámica andalusí. 20 años de investigación. Arqueología y territorio medieval. 6. Granada, I33-176.

VIGIL-ESCALERA GUIRADO, A. (2003): "Cerámicas tardorromanas y altomedievales de Madrid" en L. Caballero, P. Mateos y M. Retuerce (eds.), Cerámicas tardorromanas y altomedievales en la Península Ibérica, Anejos de AespA. XXVIII. Madrid, 37I-387. 


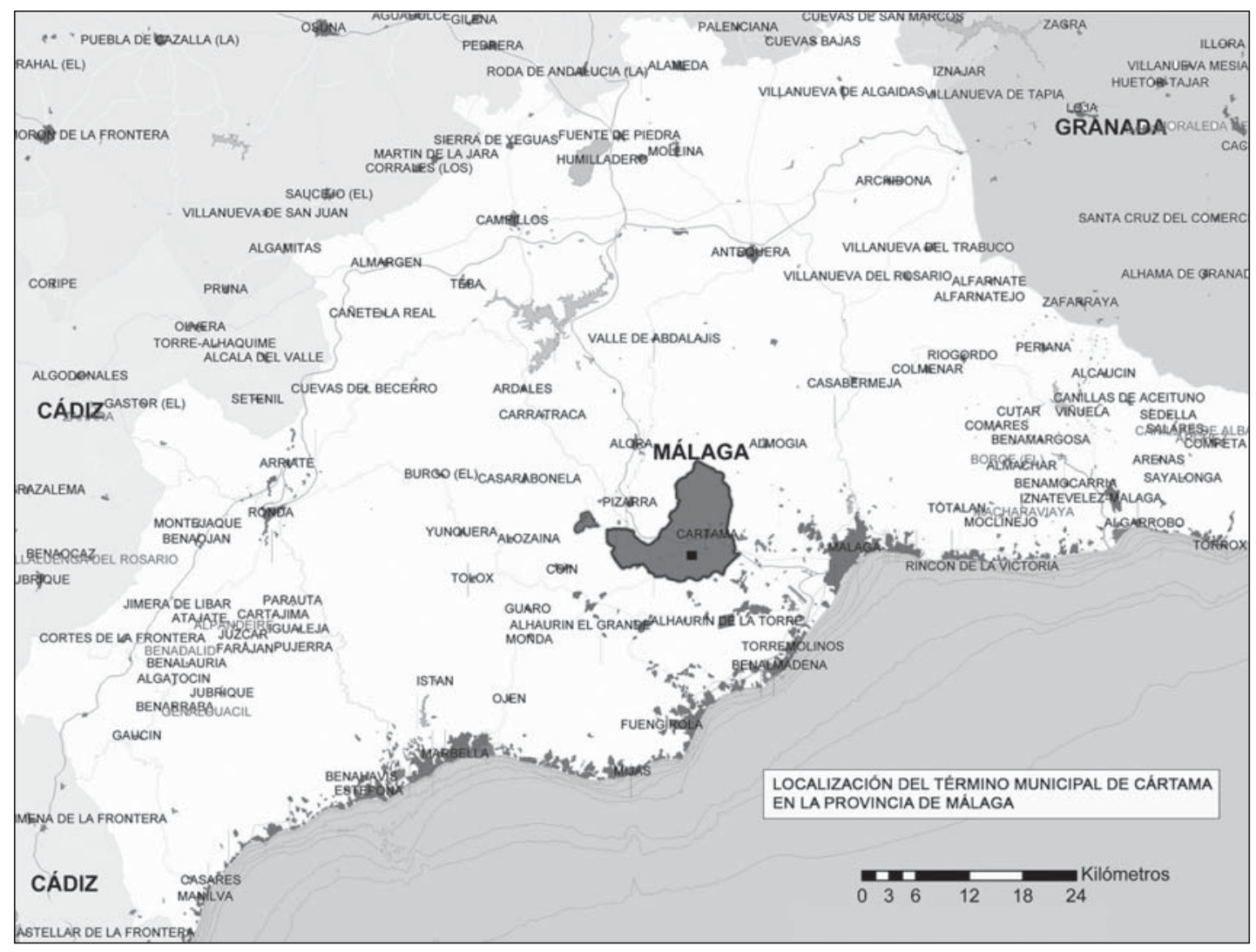

Fig. I. Localización de Cártama en la provincia de Málaga.

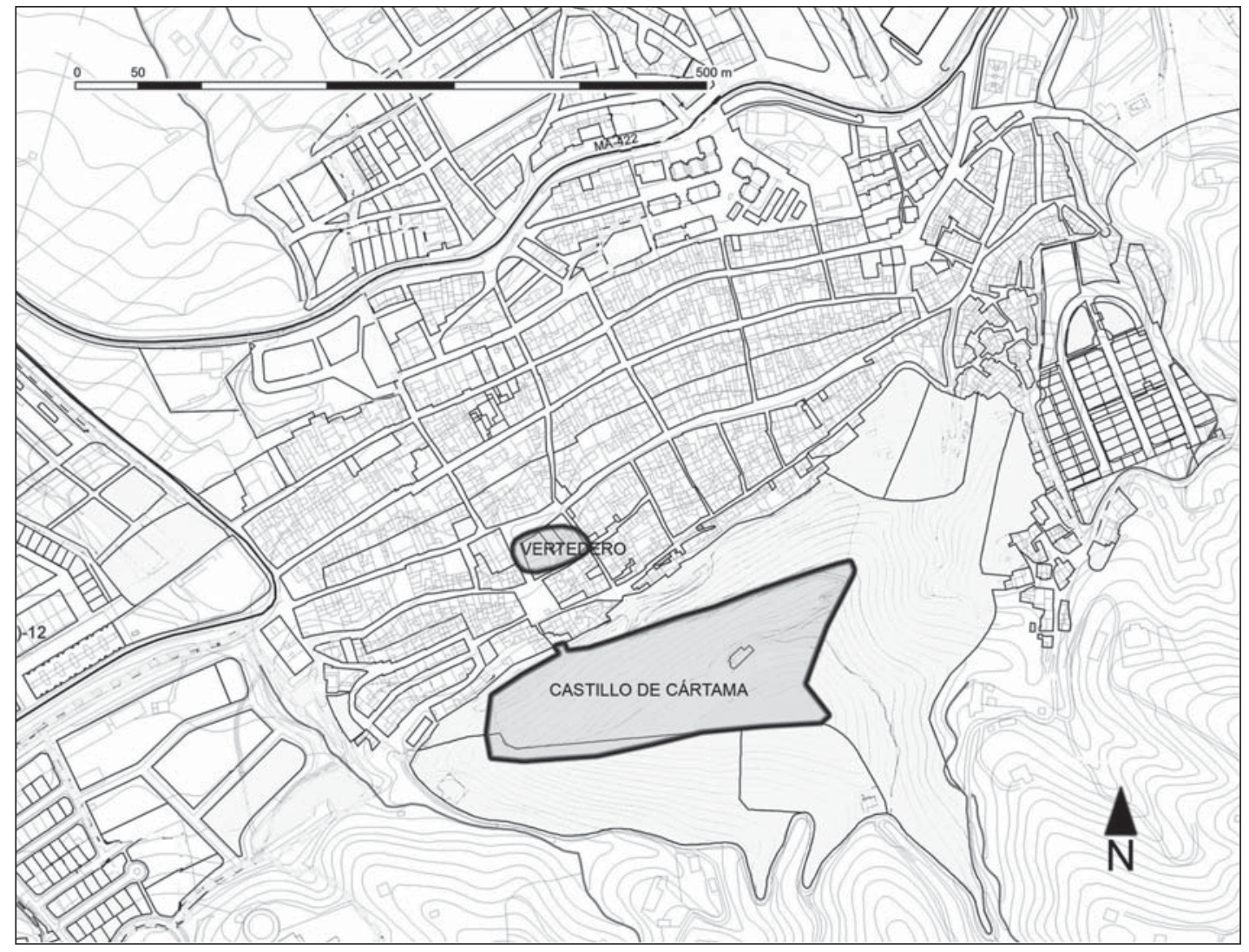

Fig. 2. Localización del castillo y vertedero de Cártama. 


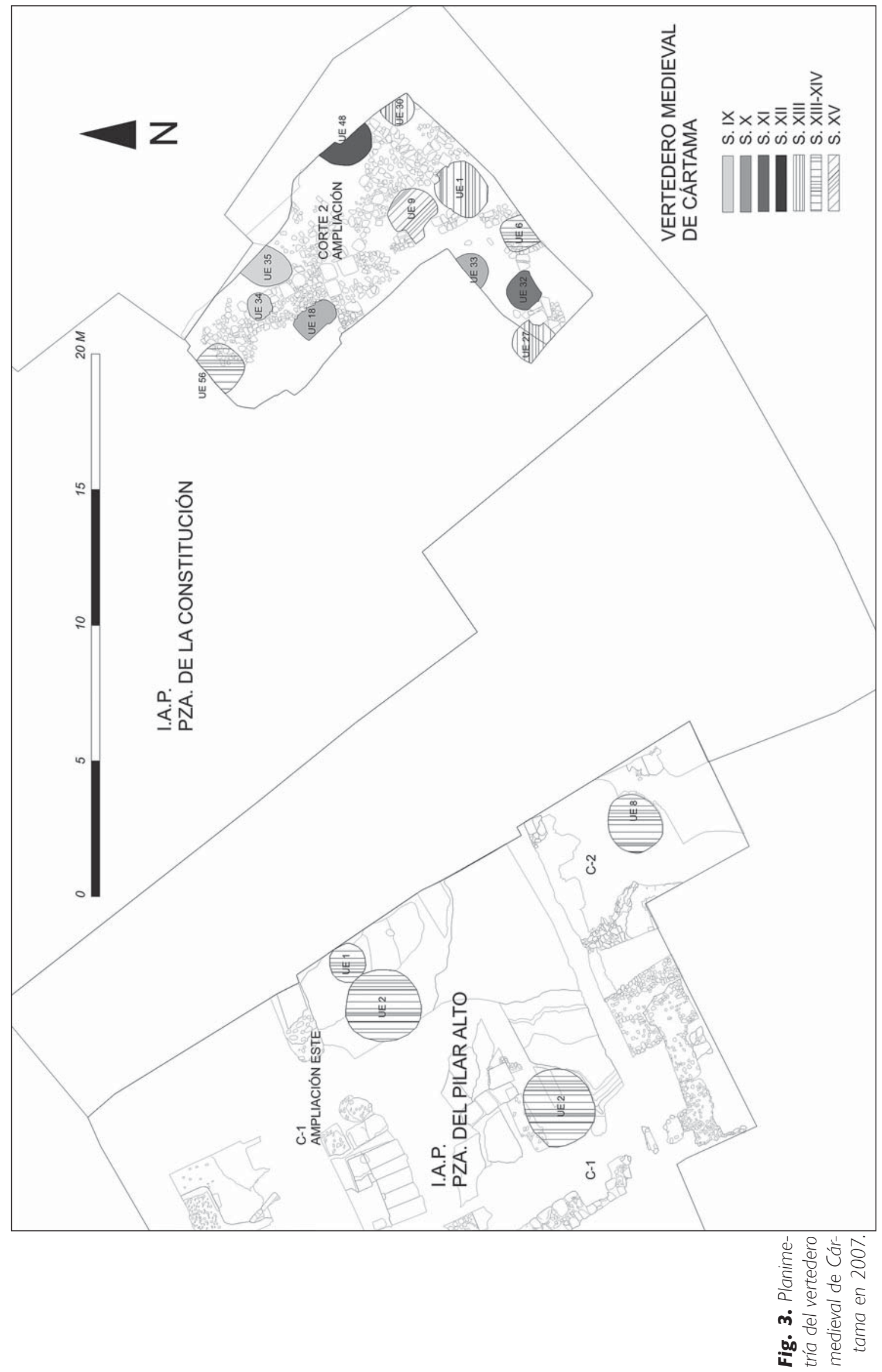




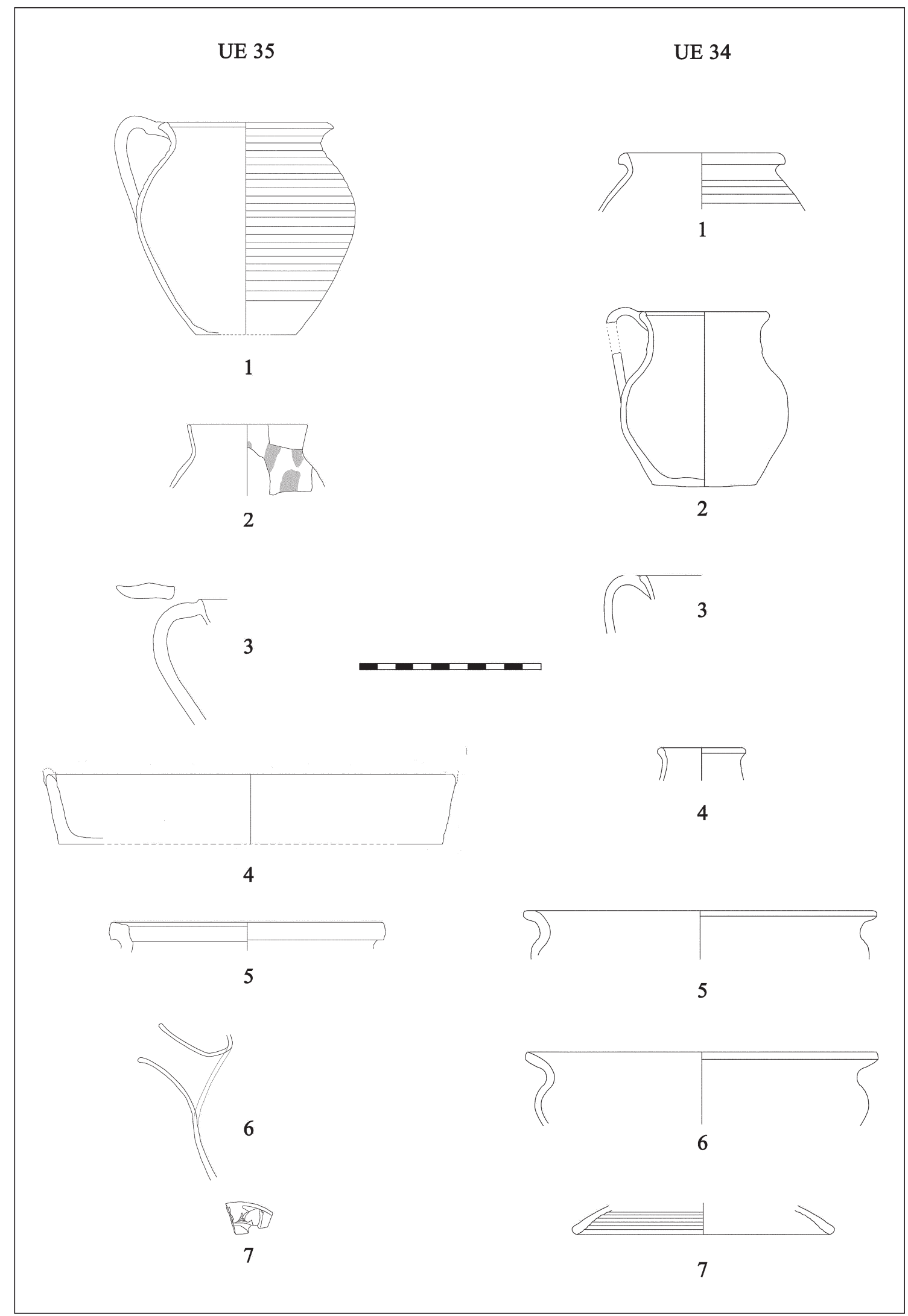

Fig. 4. Cerámicas de los pozos UUEE 34 y 35. 


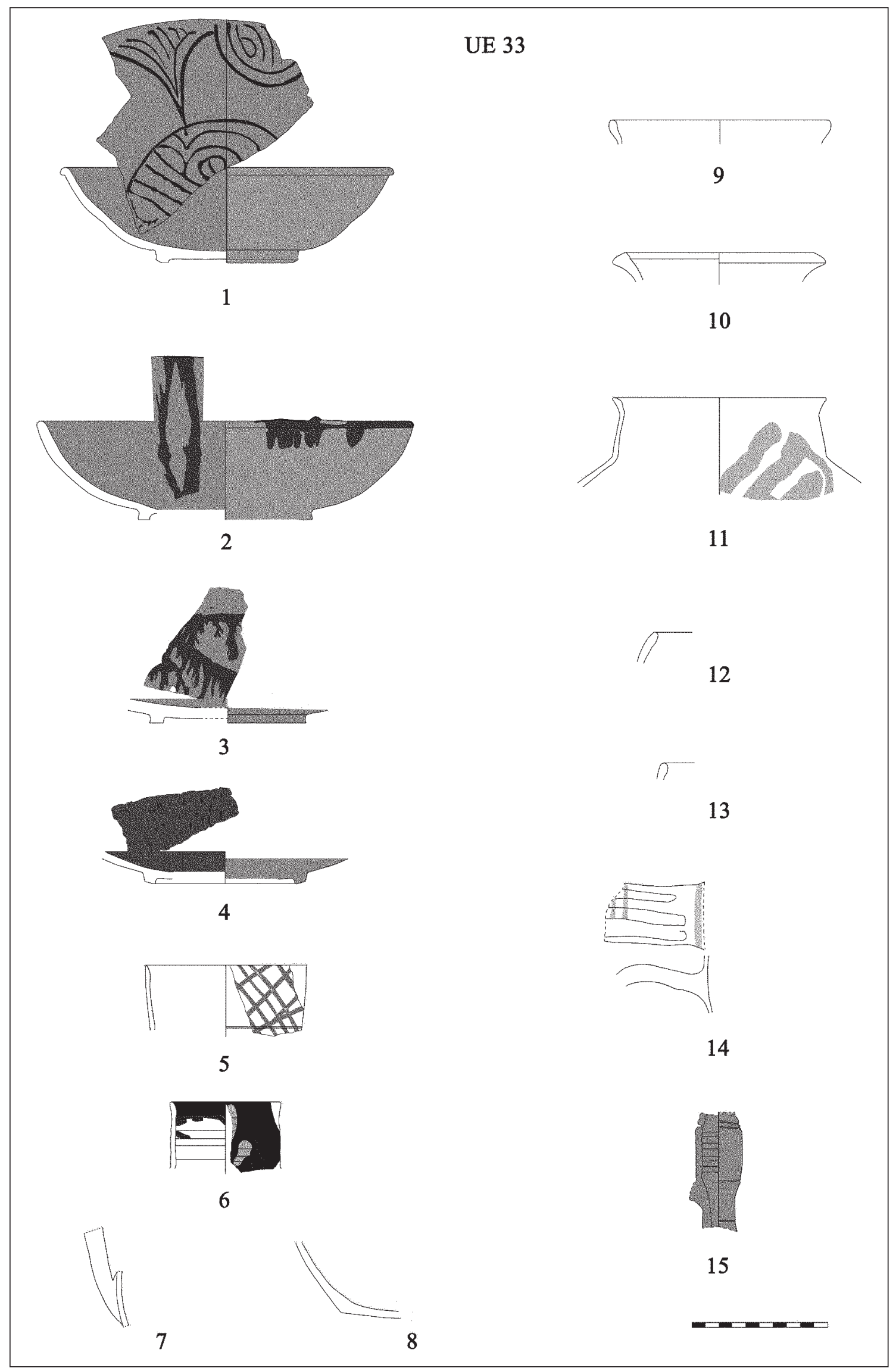

Fig. 5. Cerámicas del pozo UE 33. 


\section{UE 33}
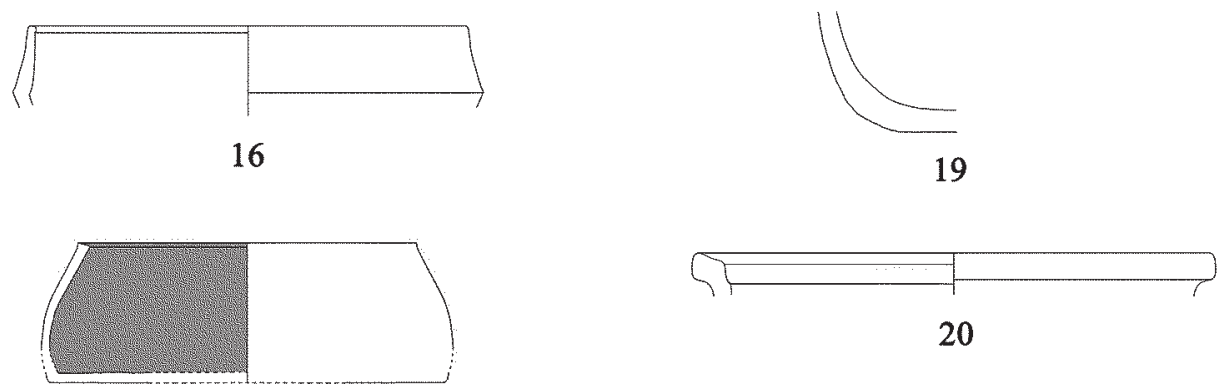

17

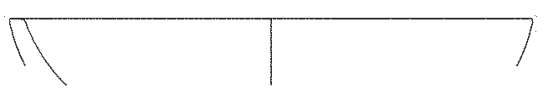

18
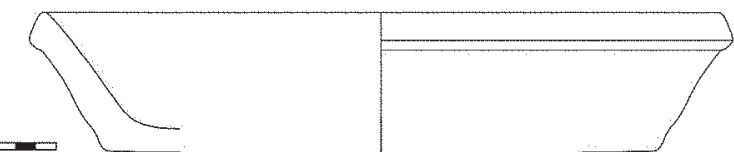

21

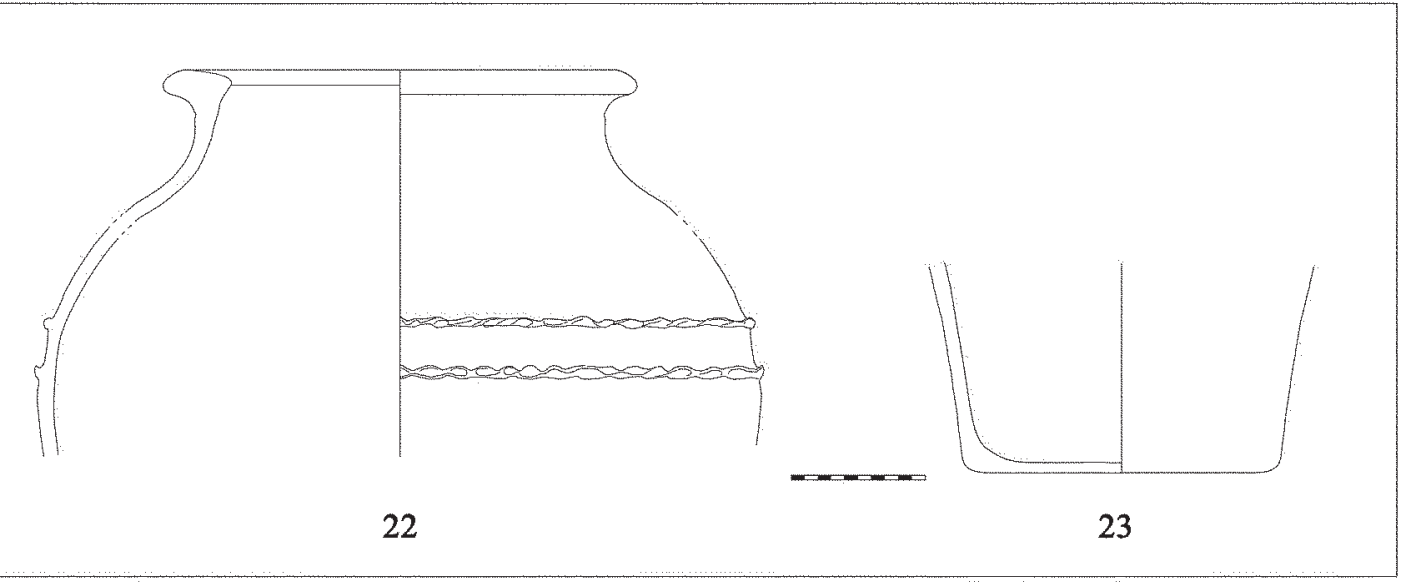

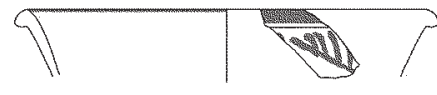

24

25

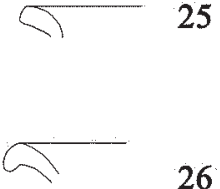

26
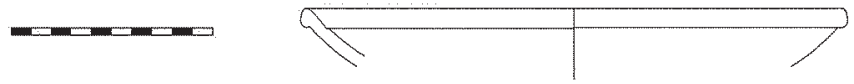

29

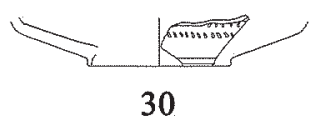

28

Fig. 6. Cerámicas del pozo UE 33. 


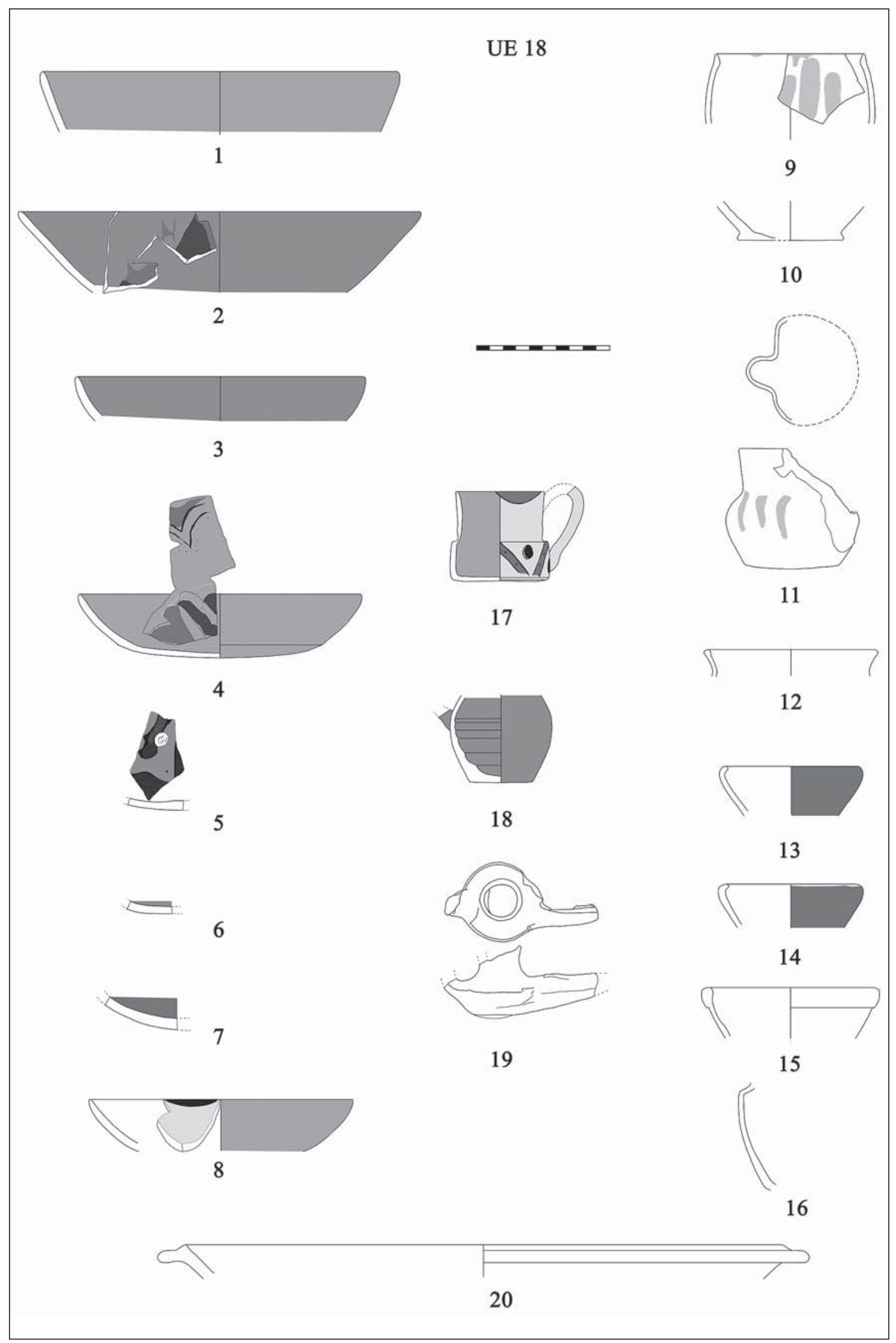

Fig. 7. Cerámicas del pozo UE 18. 


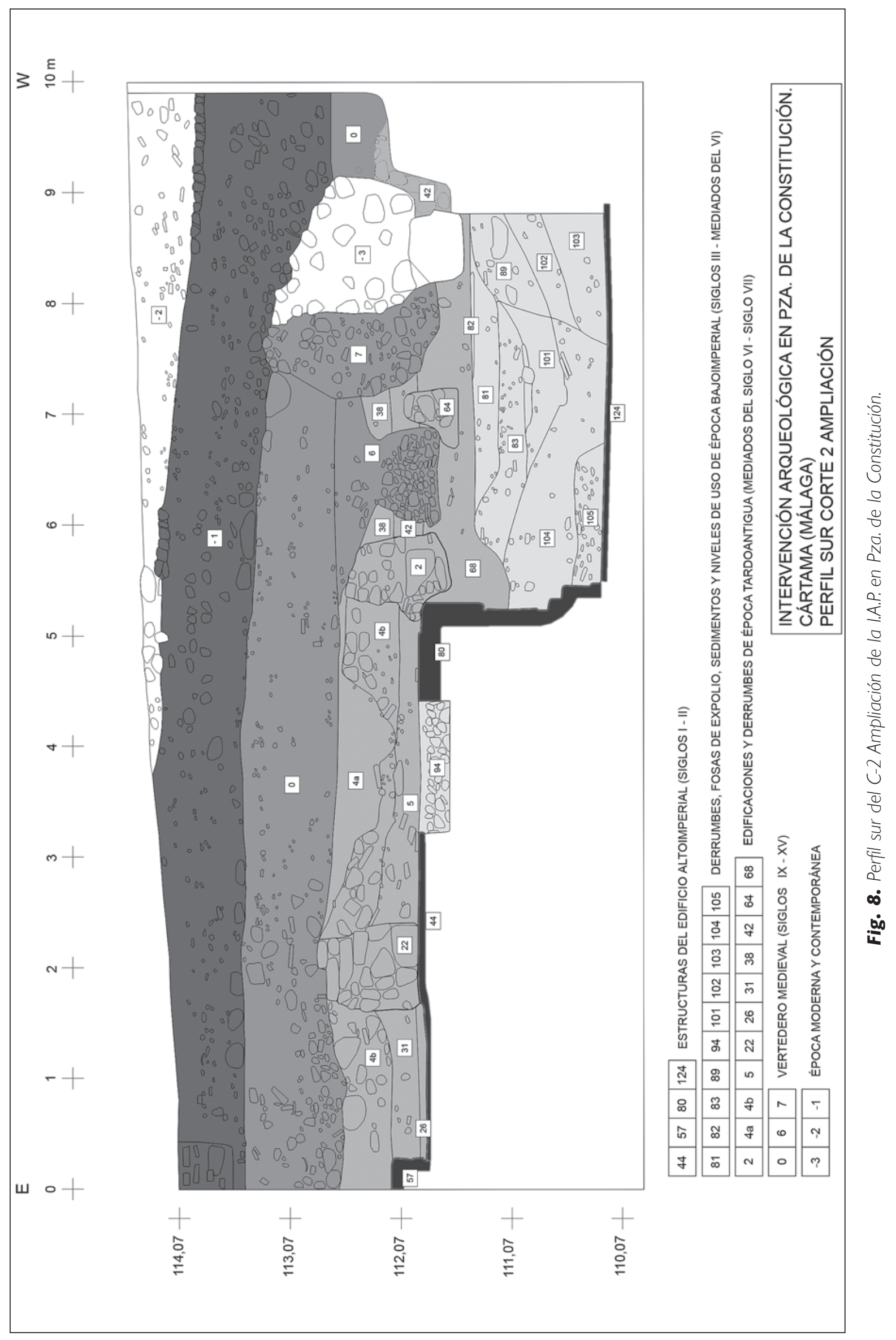




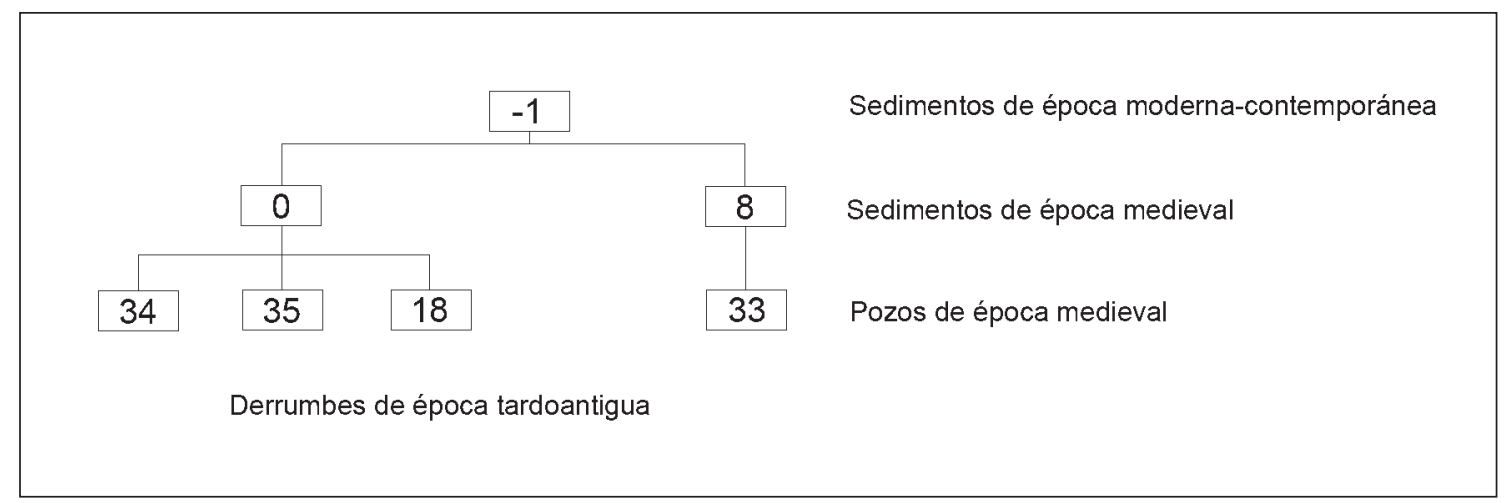

Fig. 9. Cuadro matriz.

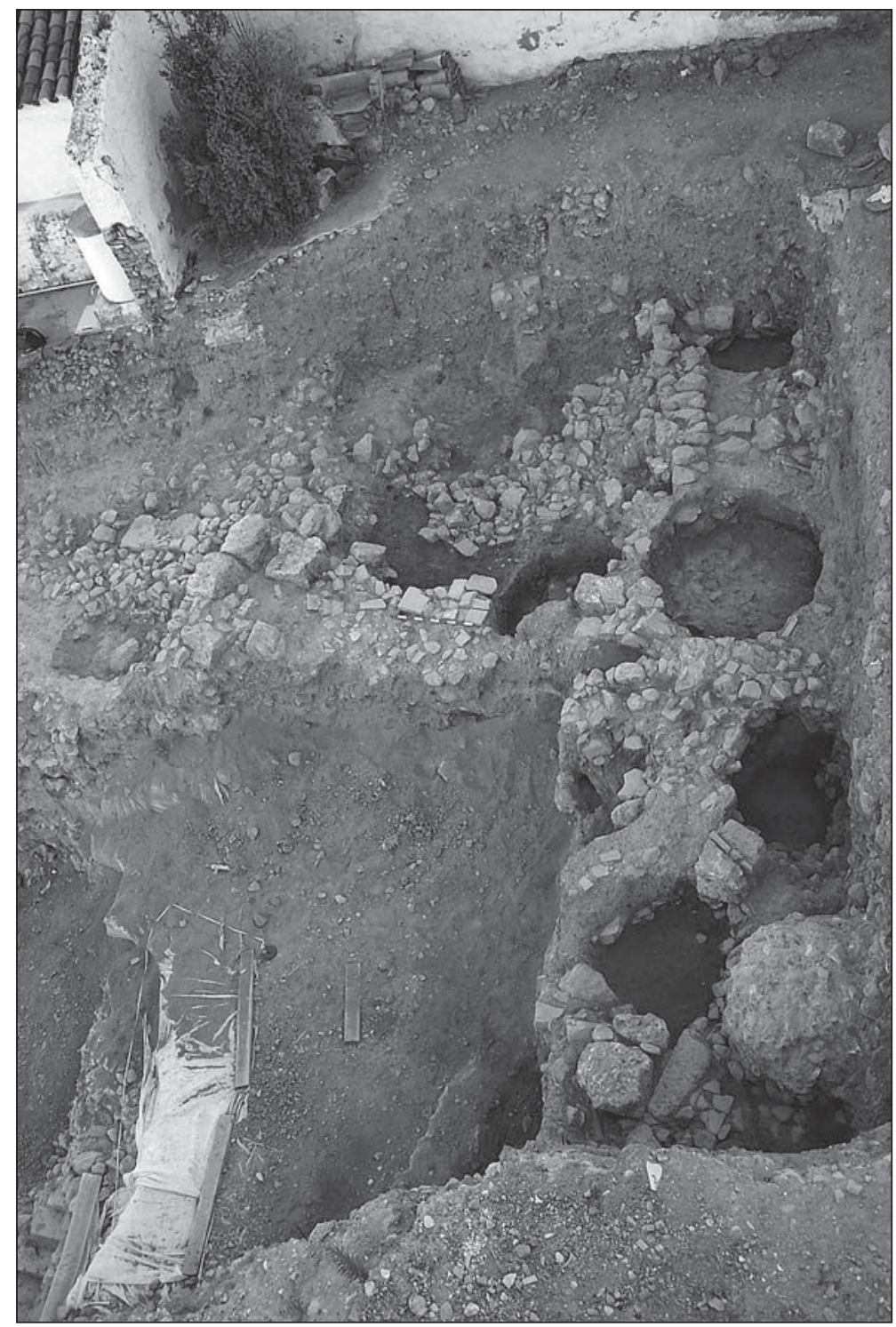

Lám. I. Aspecto del vertedero en la intervención de Plaza de la Constitución. 


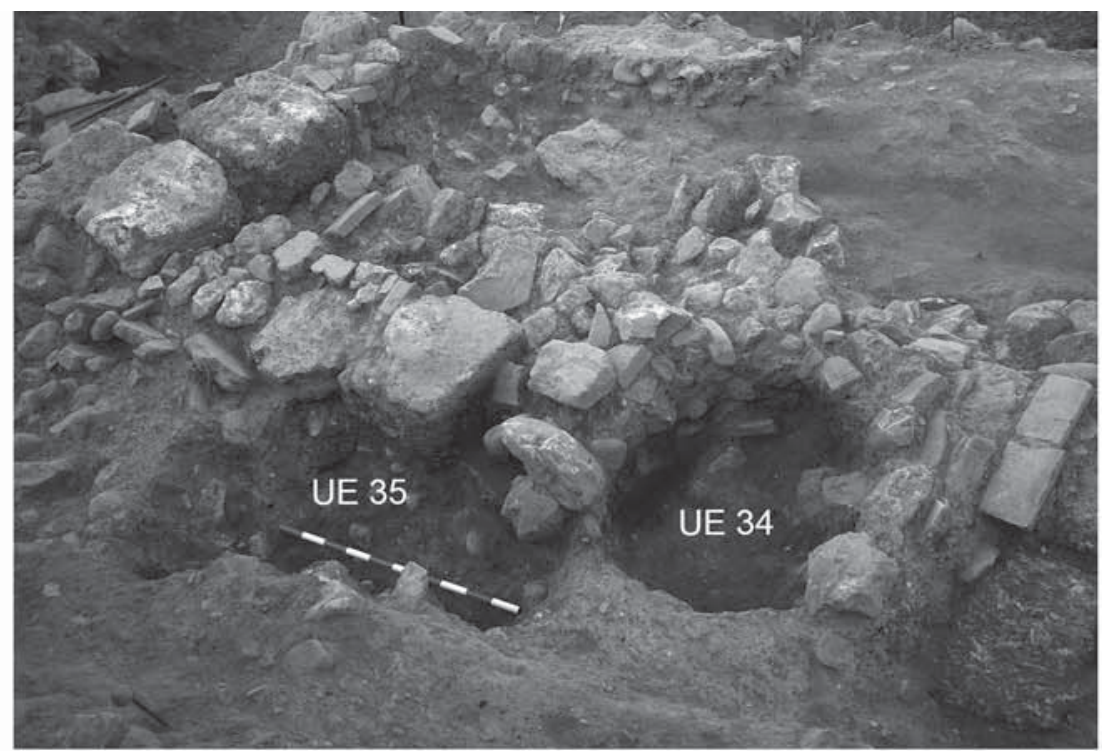

POZOS UUEE 34 y 35

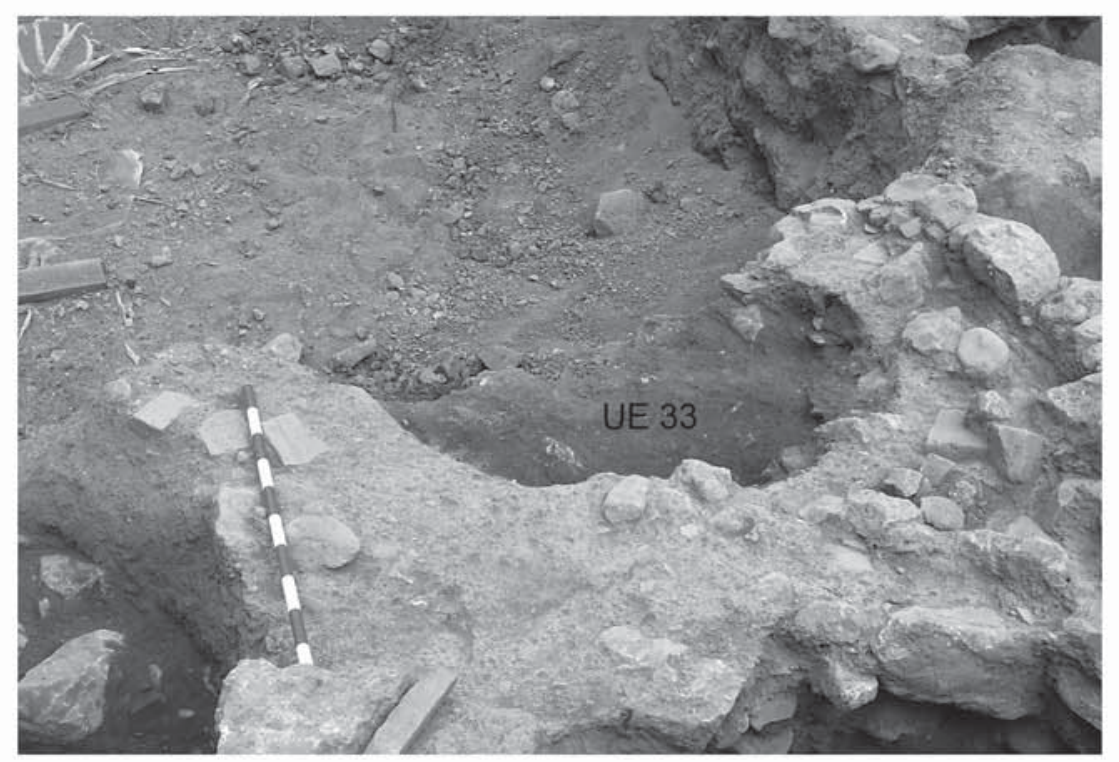

POZO UE 33

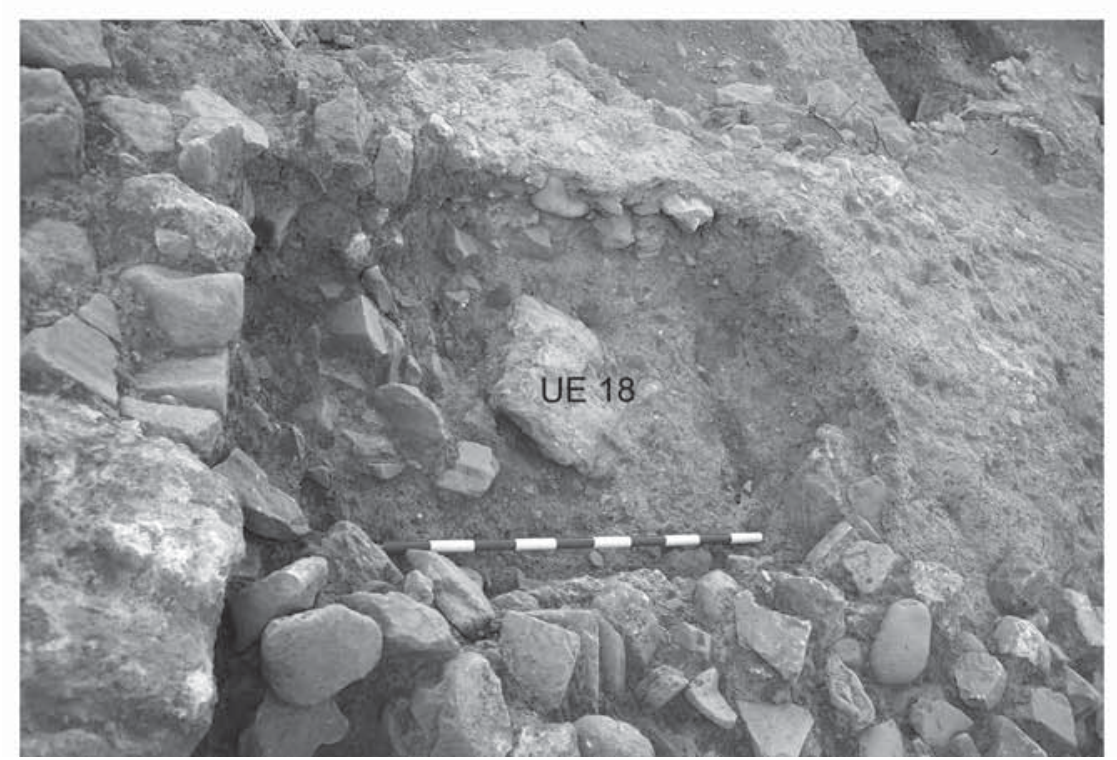

POZO UE 18

Lám. 2. Pozos de época emiral y califal del vertedero. 


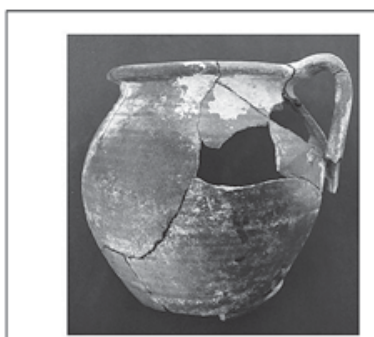

UE 35.1

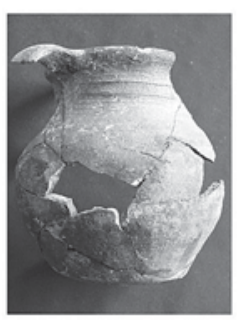

UE 34.2

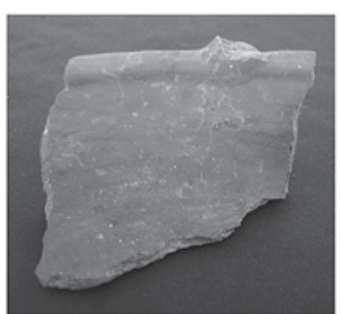

UE 35.4

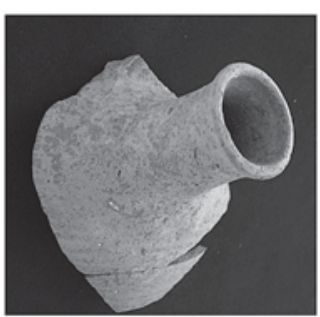

UE 35.6

FASE EMIRAL I
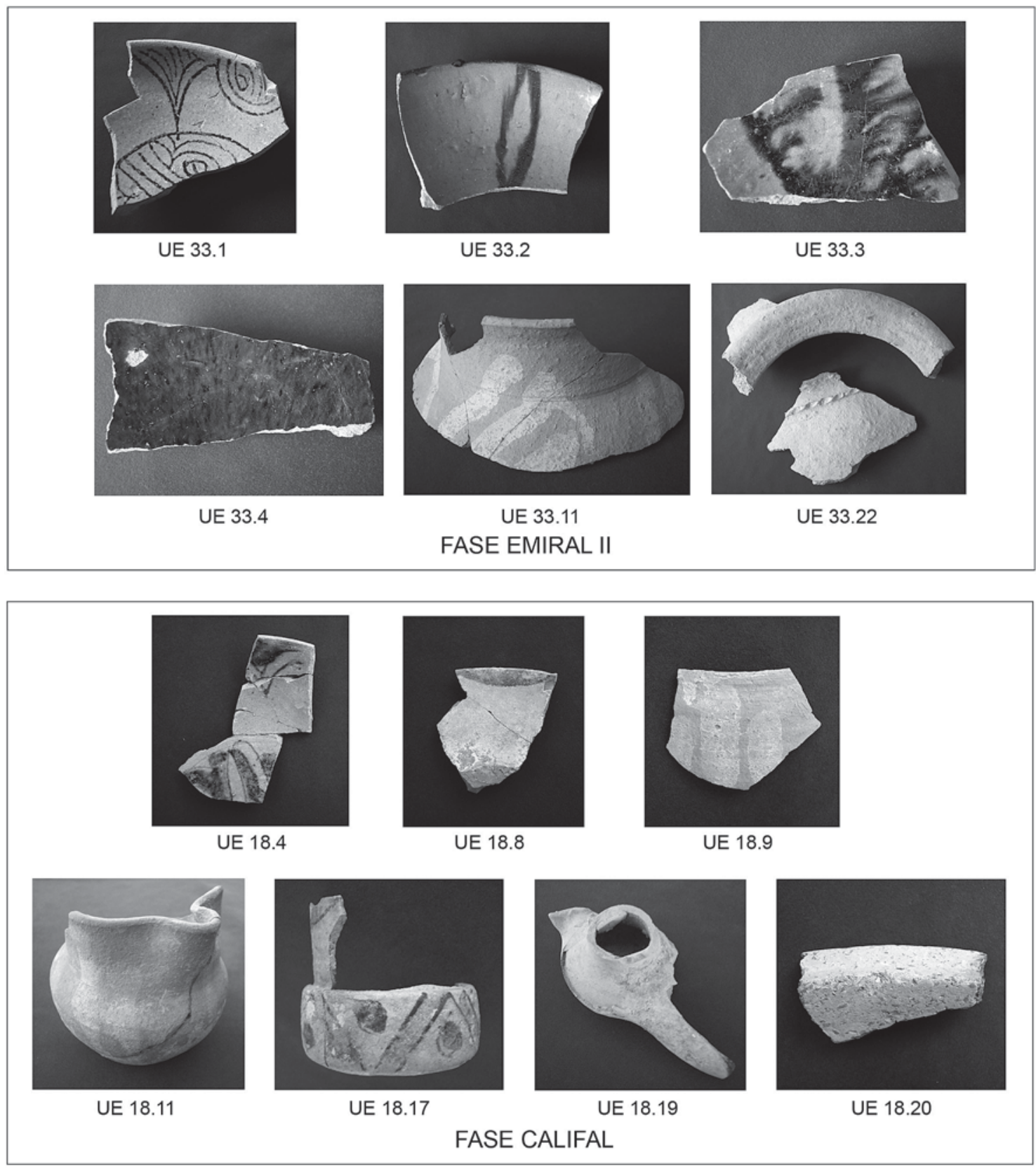

Lám. 3. Cerámicas de los pozos de época emiral y califal. 